ON THE OCCURRENCE OF RE'TINAL, HEMORRHAGE AF'TER MIDDLE AGE, ANI) I'T'S BEARING ON THE DURA'TION OF LIFE.'

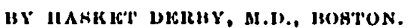

'Tes history of the following case will serve as a fitting introduction to the present paper.

Mr. X. Y., aged sixty, consulted me a few years since. From having had excellent vision for objects both far and near, assisted, of course, in regard to the latter by glasses corresponding to his years, he had only recentiy come to notice a considerable difference between the two eyes. On testing him in regard to this point I found that, while the vision of the left eye was normal, with the right eye he could barely count fingers held teu feet away. There was no external change, but the ophthalmoscope showed the pres. ence of innumerable spots of fresh hemorrhage into the retina, scattered over the entire field, as well at its periphery as in the immediate vicinity of the nerve.

Mr. Y. had been for years actively engaged in public life, had not long previously undergone much excitement and fatigue in coutesting an important election, and had only recently acted as counsel in a protracted and excited trial. He was a man of large frame and full habit, weighing probably two hundred pounds or more. He paid wo attention to physical exercise, and had for three years enjoyed no vacation whatever. Numerous affairs of consequence were even then engrossing him.

I felt justified in assuring him that the disease of the eye was probably the foreruuner of something worse, unless he wholly changed his course of life. Weakened retinal implied weakened cerebral arteries, and it was easy to realize what that meant. I advised complete rest for several months, as well as a change of surroundings.

The patient viewed the situation intelligently, and talked it over for an hour, dwelling on the absolute necessity of keeping his numerous professional engagements, and the consequences that might ensue from any neglect on his part of the important interests that had been confided to him.

This was in July, and I never saw him again. A year from the following February he came out of the court-house, iu which he had been trying a case, started to walk home, but quickly grew confused, staggered, and had to be placed in a carriage. He grew rapidly iusensible, manifested all the signs of an attack of apoplexy, never regained consciousness to a full extent, and died on the third day.

The subject of the connection of retinal hemorrhage with the condition of the geueral health is not dwelt upon by writers on ophthalmology at any length. I have looked over all the accessible literature that bas appeared since the invention of the ophthalmoscope, and have been surprised to find how little is said in regard to the matter. The subject is ordinarily dismissed in a few words. All authors are, however, agreed that, occurring in the aged, the symptom is an ominous one. While its effect on sight need be but temporary, capable as it is of a considerable measure of repair, and ordinarily affecting only a single eye, it has a bearing on the duration of life that is full of significance. It may betoken an atheromatous condi-

\footnotetext{
1 Read before the Massach usetts Medical Society, June 8, 1897, and
} recommended for publication by the Society. tion of the cerobral arteries, and be due to a similar state of things in the retinal vessels, which, however, the ophthalmoscope fails to detect. Or there may be: a cardiac lesion, ordinarily hypertrophy of the left ventricle.

'Thus the symptom is one of great importance, and the prognosis serious. 'The detection of the disense is easy for one who has a moderate acquaintance with the examination of the interior of the eye. 'The cases themselves are far from infrequent. And the warning given by their occurrence muy lo practically utilized for the regulation of important business interests. Life itself may often be prolonged by abstinence from oxhausting labor, by appropriate relaxution, and tho following a suitable regimen.

I am not aware that a series of these cases has ever been followed up, and the result given to tho profession. Many difficulties lie in the way of such an undertaking. The ophthalmic specialist differe from the fumily physician in his ability to keep track of his patients. With many, indeed it may be said with most, a single interview is all that is had. People come from points more or less distant for the purpose of consultation, and on obtaining an opinion return to their own udviser. It is very hard to learn auything relating to their subsequent history.

During the past two years I have gone over all the cases of retinal apoplexy I could find in wy records, and endeavored to obtain fresh intelligence in regard to them. By correspondence with relatives and physiciaus, as well as occasional reference to the obiluary columns of the daily press, $I$ have in some instances been enabled to follow them along. Out of ninety I have succeeded in tracing the course of eveuts in ouly thirty-one. The youngest of these patients was fortythree, the oldest eighty-three, the average age being therefore slightly above sixty-two.

Beginning with the youngest I have arranged a tabular statement as follows:

1. Male. Age forty-three. Very large single hemorrhage, of sudden occurrence. In five weeks vision had wholly returued. Fourteen years later patieut alive and well.

2. Male. Age forty-five. Numerous fine hemorrhages scattered over entire fundus. Patient, hitherto engaged in active and engrossing business, gave it up entirely and, from this time forward, led a life of comparative leisure. But the attacks recurred from time to time, and he died of cardiac disease sixteen years later.

3. Female. Age forty-six. In right eye extensive heworrhage, scattered over macular region, as well as remote parts of fundus. A single splash of blood in other eye. Vision had been for several months observed to be imperfect. Her family physiciau reported "cardiac hypertrophy, a systolic murmur, aud irregular action." Eighteen months later she was seized with convulsions, became unconscious, and died the next day.

4. Female. Age forty-six. Numerous small scattered retiual apoplexies at periphery of fundus in one eye. Vision has been obscure for several months. Examined by Dr. Kuight she was found to have wellmarked aortic regurgitation. Six mouths later she had embolism of right hawd, two days later of right foot; death supervened in a few days.

5. Female. Age forty-seven. Dark-red spot of blood directly over macula in one eye. Previous 
notes show that, ten years before, two small hemorrhages had been seen near the optic nerve, in the other eye. Dr. Knight examined the heart at that time, and found it normal. The hemorrhages disappeared. Four months after the last attack patient died of apoplexy on a railway train.

6. Male. Agre forty-eight. Vision of left eye impaired for three weeks. Numerous small spots of hemorrhage in macular region. Vision one-eighteenth. Sight was ultimately regaiued, in great measure, and the patient was reported well fourteen years later.

7. Male. Age forty-nine. Very large, fresh hemorrhage just above optic nerve of one eye. Patient much overworked, made to reliuquish business aud take a journey. Recovery complete, well four years later.

8. Male. Age fifty-8ix. Blur over right eye for six weeks. Large hemorrhage found near nerve, also numerous smaller ones at periphery of fundus. Some improvement took place, though sight was never completely restored. Died of paralysis two years later.

9. Female. Age fifty-eight. Sudden failure of vision in one eye, numerous fine retinal apoplexies found scattered over fundus. Died of cardiac disease nineteen years later.

10. Male. Age fifty-nive. Small retiual hemorrbage in one eye. Died suddenly of apoplexy, in his state-room on a steamer, about two years later.

11. Female. Age fifty-nine. Vision of one eye suddenly fell off several months ago. Numerous small retinal hemorrhages scattered about macular region. Ten months later died of apoplexy.

12. Male. Age fifty-nine. Within two weeks great failure of vision in each eye. Dilated one pupil and found numerous retinal apoplexies. Other oye similarly affected, as nearly as could be seen through the small pupil. 'This was in August, and patient died of paralysis the following winter.

13. Male. Age sixty. (Case quoted at commencement of article.) One eye affected for two weeks, enormous number of tine apoplexies. Examined in July; a year from the following February fell in the street with an attack of apoplexy, and died in three days.

14. Female. Age sixty. Fuilure of sight for two months, due to retinal hemorrhages. Eighteen wonths later died suddenly of apoplexy.

15. Female. Age sixty-two. Numerous retinal hemorrhages in one eye with corresponding failure of vision, the whole lasting six weeks. Two years later was reported to be in good health, but died of apoplexy seven years afterwards.

This patient was a sister of Case 6 .

16. Female. Age sixty-two. Within six weeks rapid failure of-vision of each eye. Large hemorrhage in each retina. Patient was six months under observation, and the hemorrhages repeatedly recurred. Is reported to have died of heart disease three years later.

17. Male. Age sixty-three. Several bright splashes of blood near lower edge of optic nerve. Had noticed trouble with eye for a week. This was the middle of Marcb. April 9 th a fresh hemorrhage was observed to have taken place. May 8 th he fell dead of apoplexy, while sitting at his desk.

18. Male. Age sixty-five. Dimness of one eye observed for a month. A number of small blood spots over macula. His physician wrote concerning him that he had valvular disease of the heart, apparently at aortic orifice, together with enlargement. Case terminated fatally in less than two months.

19. Male. Age sixty-five. A very large number of small retinal apoplexies in macular region, of recent occurrence. No apparent cause. Vision much impaired, but was subsequently regained, and patient was well and hearty seventeen years later.

20. Male. Age sixty-six. Sudden appearance of spots of retinal apoplexy over macula of one eye. Vision never returned; patient died suddenly of apoplexy three years later.

21. Male. Age sixty-six. In November, 1876, hemorrhages near right optic nerve; in April, 1877, fresh attack; in 1881 the other eye became similarly affected. In August, 1883, died of apoplexy while sitting at the table.

22. Male. Age seventy. In May, 1874, there were several small fresh hemorrhages over left macula. In 1884 patient was in good health, though vision had not returned. In 1890 is reported to have died of "old age."

23. Female. Age seventy. Retinal hemorrhages in each eye, right affected a year, left three weeks. Three weeks later died suddenly of heart disease.

24. Male. Age seveuty-two. Vision of one eye greatly impaired for six months. Numerous retinal hemorrhages. General health excellent. 'Two and a half years later saw him again, no return of vision, health as before. 'Two years afterwards had an apoplectic seizure, and at the end of two years more died of paralysis.

25. Female. Age seventy-three. One eye only affected, and that within a few days, great failure of vision, hemorrhages scattered over fundus. Patient reported to have cardiac trouble, but no opportunity for examination was offered. Five months later died of heart disease.

26. Male. Age seventy-three. Vision of left eye had been imperfect for a few months. Extensive retinal apoplexies. Two years later had paralysis of the left side, and two years after that died of uremia.

27. Male. Age seventy-four. For two months has observed what he terms a "black ball " before one eye, with much failure of sight. Retinal hemorrhages scattered in all directions. A year later died of apoplexy.

28. Male. Age seventy-six. Right eye affected two weeks, large patches of freshly effused blood in retina. Four years afterwards died of apoplexy.

29. Female. Age seventy-six. Extensive retinal hemorrhages around periphery of left fundus, failure of vision being quite recent. Nine years later died suddenly of heart disease.

30. Male. Age seventy-eight. Four days ago noticed failure of vision in left eye. Numerous bright splashes of blood surround optic nerve entrance. Came from his physician with a diagnosis of cardiac disease, there being a mitral murmur. Died of heart disease a year later.

31. Male. Age eighty-three. Left eye had failed for three years, vision now restricted to distinguishing moving hand. Large spot of effused blood over macula. Sight never returned, but the patient lived on six years, and died finally of inflammation of the bladder.

We have here then, a total of thirty-one persons, between the ages of forty-three and eighty-three, sub- 
jects of retinal hemorrhage. 'Twenty-five of these died after brief illnesses, some indeed with the utmost suddenness. Eleven of this number died of heart disease, fourteen of apoplexy. Five were at last accounts living, their average age being tifty-four, and their cases followed up an average of thirteon years. Another, a man of eighty-three died, six years after he came to we, of an affection of the bladder.

While, therefore, the effusion of blood in the retina cannot be said to uniformly portend danger to life, it has certainly a grave siguificance, increasing directly with the age of the patient. That it is often overlooked thero can be no question. Within a few days I received a visit from a lady aged seveuty, who had consulted me fourteen months before. 'The eyes were then examined separately, both as to vision and ophthalmoscopically, and found to be in the condition that would be expected at her time of life. She saw distant objects with either eye equally well. On the occasion of her second visit she complained that the use of her glasses had of late beeu attended with difficulty, and she found it impossible to support the continued use of the eyes on near objects. She came supposing that she needed a change of glasses. One eye remained normal, while the vision of the other had fallen off nine-tenths, and there were numerous retiual apoplexies. Of the occurrence of this accident she had not the least idea. Unwilling to alarm her I stated the case to the daughter who accompanied her, gave directions for the treatment of the patient, and wrote to her son, advising a speedy arrangement of any untinished business matters.

And this is the practical point involved. An early diagnosis, and the consequent recoguition of the possibility of sudden death, not ouly leads to the settlement of business interests that, in the event of an unexpected demise, might seriously suffer; but causes advice to be given that may sensibly prolong the days of the patient. Auscultation, thus suggested, may detect the presence of an hitherto unsuspected cardiac lesion. And in any case suitable diet, leading a regular life, and above all the avoidance of exhausting work or excessive meutal activity, have lengtheued many a life thus threatened. I cannot doubt but that, if the patient mentioned in the commencement of this paper had followed the advice that was earuestly given him, had retired from his engrossing and exhausting work and taken the vacation he so much needed, a valuable and valued life wight have beeu long preserved to the community. He was a man of powerful physique, and appareutly in the prime of his powers, both bodily and mental, when the apoplectic seizure, of which he had full warniug, came so suddenly upon him.

These cases must of course be referred back by the specialist to the fanuily physician, to whom indeed their diagnosis ought to be by no means impossible. The patient is generally advanced in years, vision is suddenly impaired, and in a single eye, a general mist or blur being the symptom complained of. Cataract makes its presence more gradually felt, while glaucoma can be recognized by the tension of the eyeball, the enlargement of the pupil, and the characteristic eucroachment on the visual field. If there is no reason to suspect either of these diseases, a retinal bemorrhage is, under the circumstances already men. tioned, at least probable. 'To eularge the pupil, which is ordinarily necessary, a weak solution of scopolamine may be used, and the degree of fawiliarity with the ophthalmoscope, which now does or should enter into the training of every physician, enables the observer to make a vertain diagnosis.

\section{Medical Progregg.}

\section{REPOR'T ON PROGRESS IN 'THERAPEUTICS.}

HY FIEANOIS H. WIILIAMK, M.D., IBH'TON.

NEW I'RKPARATIONS OF 'TUBERCUI.IN.'

Dr. Robert Kocn, in this article, begins by discussing two kinds of immunity - the ono andinst toxins and the other against the bacteria - and goes on to say that the ideal immunity is that which will protect the human body not only against one of the injurious agents but against all of the injurious agents produced by pathogenic micro-organisms; and these considerations play a great rôle in tuberculosis. All attempts made to secure in any numbers the absorption of unchanged living or even dead tuberclo bacilli by the subcutaneous tissue, by the peritoneal cavity or by the circulation, failed; and as it was then proved that bacilli in an uuchanged state could not be used for purposes of immunization, an endeavor was made to render the bacilli absorbable by some chemical attack, and to this end they were treated with dilute mineral acids or with strong alkalies under boiling heat. As this also failed of its purpose, the absorbable constituents were extracted from a mass of tubercle bacilli in order to use them for purposes of immunization; and experineuting with glycerine extraction led to the dis covery of tuberculin.

Tuberculin has the valuable property of producing a characteristic reaction in animals and man affected with tuberculosis, when introduced subcutaneously in very small quantities, and may be utilized in the recognition of tuberculosis in the earliest stages. The fear that, in consequence of the reaction, the tubercle bacilli would be rendered mobile and would then be transmitted to bealthy animals, has been shown in many thousands of tuberculin injections, made upon cattle us a test, to be perfectly groundless.

The further use of tuberculin consists in its employ. ment in the treatment of tuberculosis. As an uumistakable improvement in the tuberculous process occurs after every reaction produced by tuberculin, it would seem proper to continue the reaction as long as any improvemeut shows itself. But this improvement cannot be indefinitely continued, as the reaction agaiust tuberculin is gradually lost, and with it, of course, the effect of the tuberculin; so that, finally, there comes a period of perfect immunization against the tuberculiu, and this period may last for several months. This immunization has no effect upon the tubercle bacilli themselves, it is a pure toxic immunity, and not a bacterial immunity. Unfortunately, the reaction agaiust tuberculin is very often lost before there is anything like a perfect cure of the disease, and a relapse sets in which must again be treated with tuberculin reactions so soon as the capability of reaction is established. Still, treated in this way, with the necessary skill and patience, a cure, or at least very great

1 Deutsche med. Woch., April 1, 1897, trauslation in Ciucinaati Lancet-Clinic, April 24, 1897. 